\title{
28 Research Square \\ Spatio-Temporal Analysis of Summer Salinity Fronts in the Greenland Sea
}

Jianhui Wang

Zhejiang Ocean University

Yu Liu ( $\square$ liuyuhk@zjou.edu.cn )

Zhejiang Ocean University

\section{Guoqing Han}

Zhejiang Ocean University

Xiayan Lin

Zhejiang Ocean University

Guijing Yang

Zhejiang Ocean University

\section{Research Article}

Keywords: Spatio-temporal analysis, summer salinity, Greenland Sea, global ocean eddy resolution reanalysis, horizontal gradient, sea ice

Posted Date: August 11th, 2021

DOl: https://doi.org/10.21203/rs.3.rs-789378/v1

License: (c) (i) This work is licensed under a Creative Commons Attribution 4.0 International License.

Read Full License 


1

\title{
Spatio-temporal analysis of summer salinity fronts in the Greenland Sea
}

\author{
Jianhui Wang ${ }^{1}$, Yu Liu ${ }^{* 1,2}$, Guoqing Han ${ }^{1}$, Xiayan Lin ${ }^{1}$, Guijing Yang ${ }^{1}$

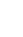 \\ ${ }^{1}$ Marine Science and Technology College, Zhejiang Ocean University, Zhoushan, 316000, China. \\ ${ }^{2}$ Southern Marine Science and Engineering Guangdong Laboratory (Zhuhai), Zhuhai, 519000, China.

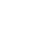

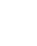

0

* Corresponding author address: Yu Liu

22 Marine Science and Technology College, Zhejiang Ocean University, Zhoushan, China.

23 Email: liuyuhk@zjou.edu.cn 


\section{Abstract}

Using daily average data from the global ocean eddy resolution reanalysis product (GLORYS12V1) from 1993 to 2018, sea surface salinity horizontal gradient is calculated to obtain the spatio-temporal distribution and the intensity characteristics of the salinity front in the Greenland Sea. Combined with the sea ice concentration data, the salinity front and sea ice relationship is also studied. There is a significant spatial relationship between the main position of the salinity front and the ice edge before the sea ice shrinks toward the continental shelf. In the climatological seasonal variation, the intensity of the salinity front beyond the continental shelf reaches its strongest $(\sim 0.22 \mathrm{psu} / \mathrm{km})$ in July. The front area beyond the continental shelf reaches its peak value $\left(\sim 7.80 \times 10^{4} \mathrm{~km}^{2}\right)$ in August. The interannual variation of sea ice extent averaged from July to August has a downward trend of $5.83 \times 10^{3} \mathrm{~km}^{2} / \mathrm{year}$. Under the background of rapid change in sea ice, the intensity and area of the salinity front beyond the continental shelf are reducing at about $1.7 \times 10^{-3} \mathrm{psu} / \mathrm{km}$ and $142 \mathrm{~km}^{2}$ /year, respectively.

\section{Introduction}

The Greenland Sea, one of the main marginal seas in the Arctic Ocean, is located to the east of Greenland. Its shelf slope area is covered by sea ice all-year-round, and its dynamic thermal environment is affected by sea ice formation and melting. The Greenland cold current flows southward along the shelf break. The daily mean current on July 15, 2018 is shown in Fig. 1. 


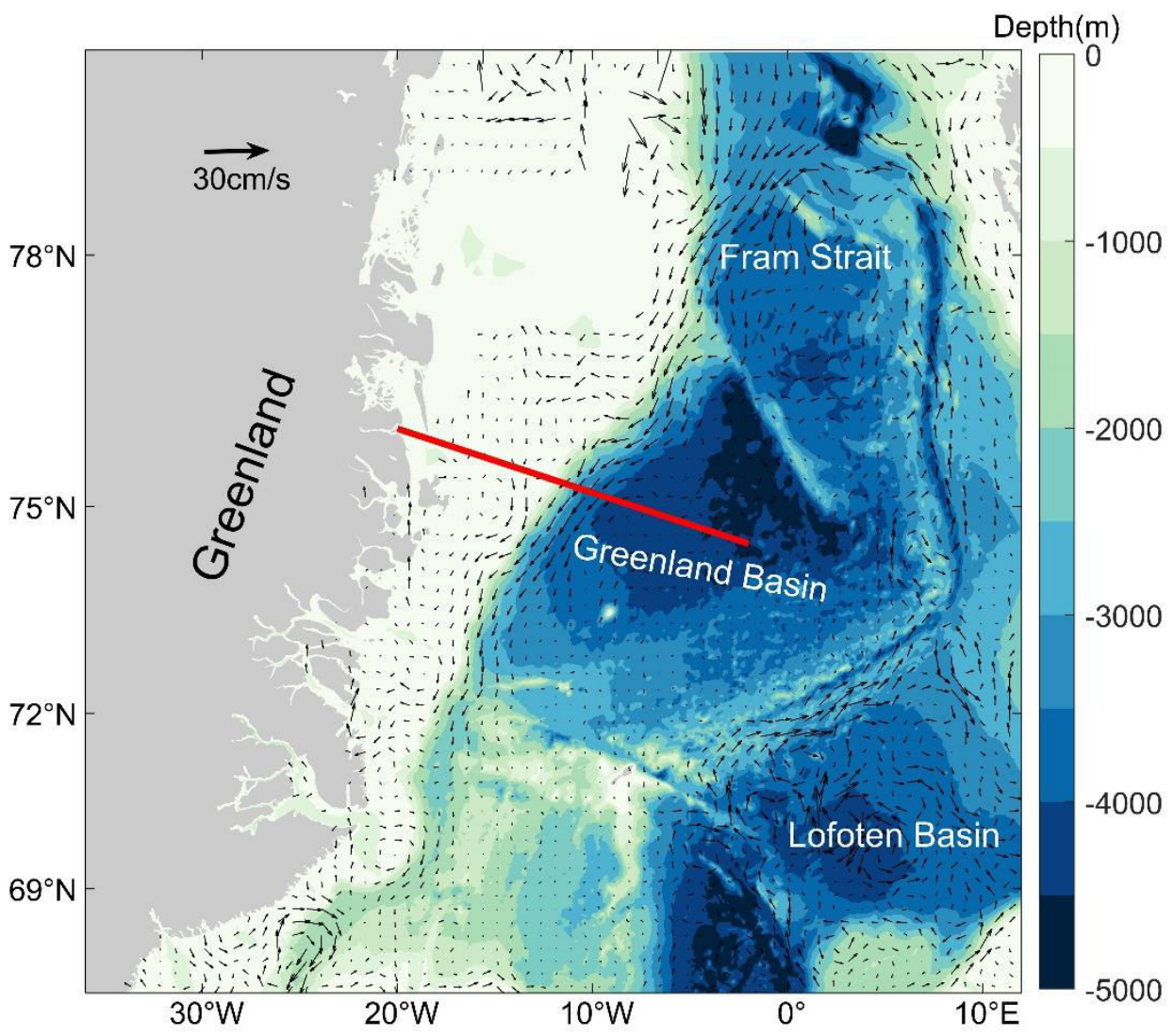

Figure 1. Topography of the Greenland Sea. The background color is the bathymetry, taken from ETOPO $1^{1}$. The black arrows are the geostrophic current field on July 15, 2018. The red line is the section selected for further analysis.

There are various complex mesoscale ocean-sea ice-atmosphere interactions in the marginal ice zone. The salinity front is one of the most significant marine phenomena in the Greenland Sea during Arctic summer ${ }^{2}$. When the sea ice melts, the freshing seawater forms in the ice zone, and a strong horizontal surface salinity gradient appears along the marginal ice zone, forming a salinity/density front. From previous studies using observation data, there is a high temperature and salinity core of Mid Atlantic water along the polar front of East Greenland ${ }^{3}$, with significantly different currents on both sides of the front ${ }^{4}$. The wind stress above the front zone also changed rapidly ${ }^{5,6}$.

Previous studies have shown a relationship between the position of the oceanic front and the ice edge location in the Pan-Arctic region ${ }^{7,8,9,10}$. Based on a cruise observation in the Bering Sea in Spring 1982, the ice edge retreated at $6 \sim 38 \mathrm{~cm} / \mathrm{s}$. The 
upper ocean front also moved fast and kept pace with the retreating ice edge, but the deeper front was nearly stationary ${ }^{7}$. The $\sim 3$-day evolution of a density front located at the ice edge in the Beaufort Sea was captured by an underway conductivity-temperature-depth system. In the same period, the synthetic aperture radar image also showed that the ice edge underwent concurrent evolution ${ }^{11}$.

The formation and melting of sea ice play an important role in global climate change ${ }^{12,13,14}$. The sea ice in the Greenland Sea has been changing rapidly in recent years, and this change also affects various ocean processes, including ocean fronts ${ }^{15,16}$. The ocean front is considered to be an important factor in the energy transfer chain from global-scale circulation to small-scale phenomena ${ }^{17}$. It can affect the structure of the ocean flow field, ocean heat exchange, material transport and air-sea interaction ${ }^{18}$. In addition, various oceanic or atmospheric phenomena and processes are related to the ocean front, such as high biological productivity, abnormal wind and waves, dramatic changes in ocean color, strong vertical motion and local weather conditions. Large-scale fronts can influence the weather and even the climate ${ }^{19}$. Therefore, the variation of fronts under the background of the rapid change in sea ice is an important point for research.

The horizontal gradient of the climatological sea surface salinity in the Nordic Sea is not greater than $0.001 \mathrm{psu} / \mathrm{km}$. Some researchers considered the spatial and temporal variations of the oceanic front. They defined a salinity front threshold as $0.002 \mathrm{psu} / \mathrm{km}$ in the Nordic Sea to research the distribution characteristic of the salinity front and its seasonal variation ${ }^{2,20}$. Since an oceanic front is a mesoscale phenomenon, the position and intensity of a front cannot be accurately defined using climatology and low-resolution data.

In order to obtain the salinity front variation as accurately as possible, we use a multi-year daily average reanalysis data to study the spatial distribution and intensity characteristics of the salinity front beyond the continental shelf in the Greenland Sea from July to August (JA). We also investigate the interannual variations of the salinity front under the background of sea ice shrinking. 


\section{Results}

As the sea ice melts in the Greenland Sea from June to August, the sea ice extent shrinks toward the continental shelf, and the salinity front moves and keeps pace with the ice edge. The spatial distributions of the ice edge and the horizontal gradient of the sea surface salinity in the Greenland Sea from June to August of 1993, 2007, and 2015 are shown in Fig. 2. The black line is the daily marginal ice line, and the purple line is the $330 \mathrm{~m}$ isobath and represents the shelf break.

On June 29, 1993 (Fig. 2a), the ice edge is located outside the shelf break. Its southernmost point reaches $68^{\circ} \mathrm{N}$ and the overall sea ice extent shrinks toward higher latitudes. On July 16, 1993 (Fig. 2b), the ice edge is near the continental shelf break. The sea ice continues to retreat northwestward while the ice edge meanders in the continental shelf. On the $31^{\text {st }}$ of August (Fig. 2c), the sea ice extent is minimum and its southernmost point is at $69.6^{\circ} \mathrm{N}$. In most years, the sea ice covers the continental shelf north of $77^{\circ}$ N. Compared with 1993, the ice edge in 2007 (Fig. 2d-2f) and 2015 (Fig. 2g-2i) have a similar seasonal variation, but the sea ice extent shrinks more significantly.

When the ice edge is outside the shelf break (Fig. 2a, d, g), the strong salinity gradient is mainly concentrated at the ice edge. During the northward movement of the ice edge, the front moves and keeps pace with the ice edge. When the sea ice retreats toward the continental shelf, the front is limited to the shelf break (Fig. 2c, f, i), and the intensity and area of the front gradually decrease. 

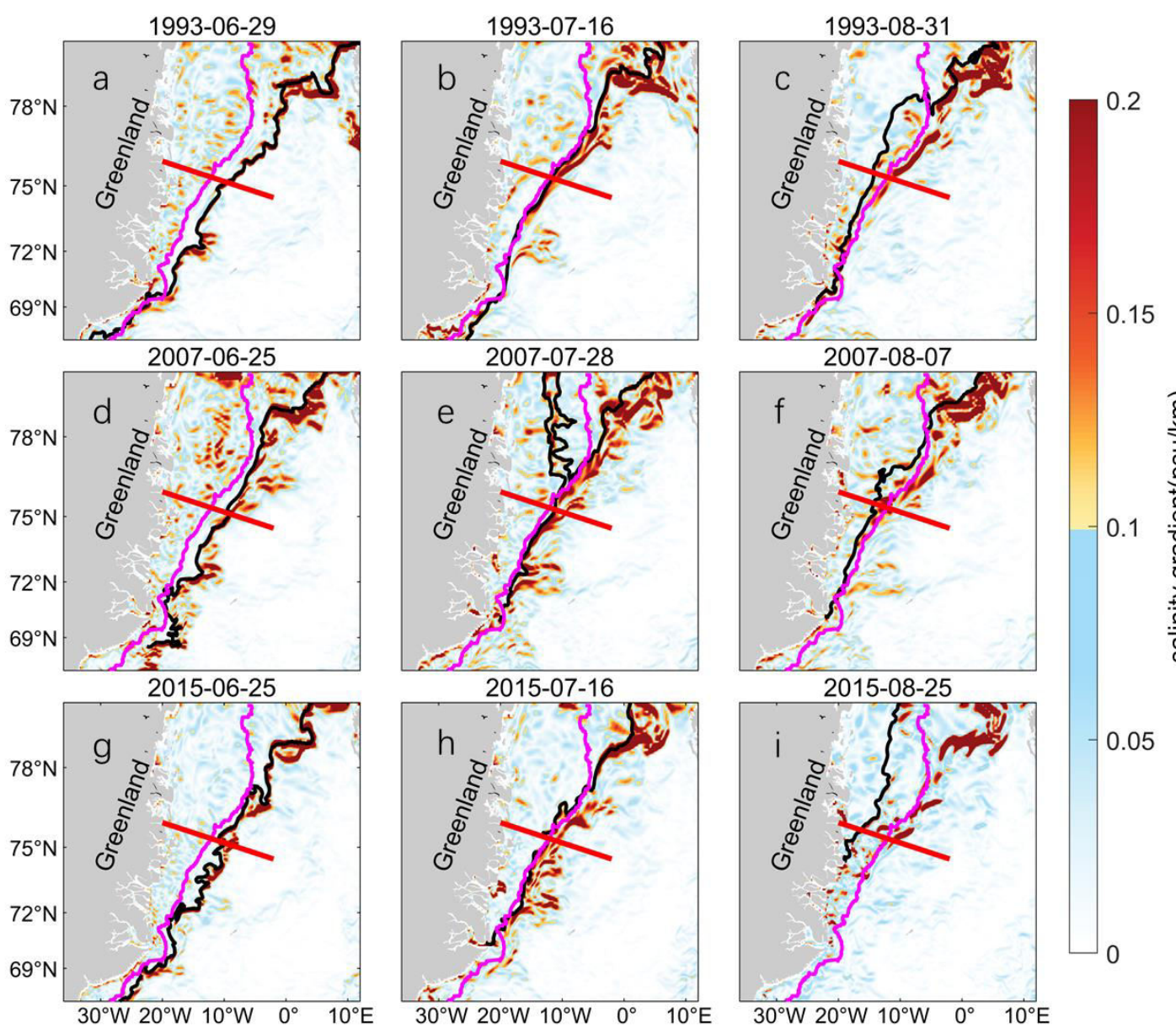

Figure 2. The spatial distributions of the ice edge and the horizontal gradient of the sea surface salinity in the Greenland Sea from June to August of 1993 (a-c), 2007(d-f), and 2015 (g-i). The black line is the daily marginal ice line, and the purple line is the $330 \mathrm{~m}$ isobath and represents the shelf break.

To clarify the relationship between the position of the salinity front and the ice edge in the Greenland Sea, we select a section (red line in Fig. 1) to analyze the relative position changes compared with the shelf-slope break. The daily variation of the salinity and horizontal salinity gradient along the section in 2007 is shown in Fig. 3. In June, when the sea ice concentration is lower, the seawater under the ice is fresher and a strong salinity gradient appears. The intensity of the salinity front strengthens from July to August. At the end of September, the salinity front gradually weakens.

When the sea ice (black dots in Fig. 3, which indicate the intersections of the ice edge line and the section) is beyond the continental shelf from June to August (solid 
black lines in Fig. 3, which indicate the intersections of the section and shelf break), the salinity front is always distributed along the ice edge and keeps pace with the ice edge. When the sea ice shrinks back to the continental shelf (black dots below the solid black line), the salinity front is restricted to the vicinity of the shelf break due to the sufficient mixing of the seawater in the continental shelf. However, its intensity is gradually reduced.
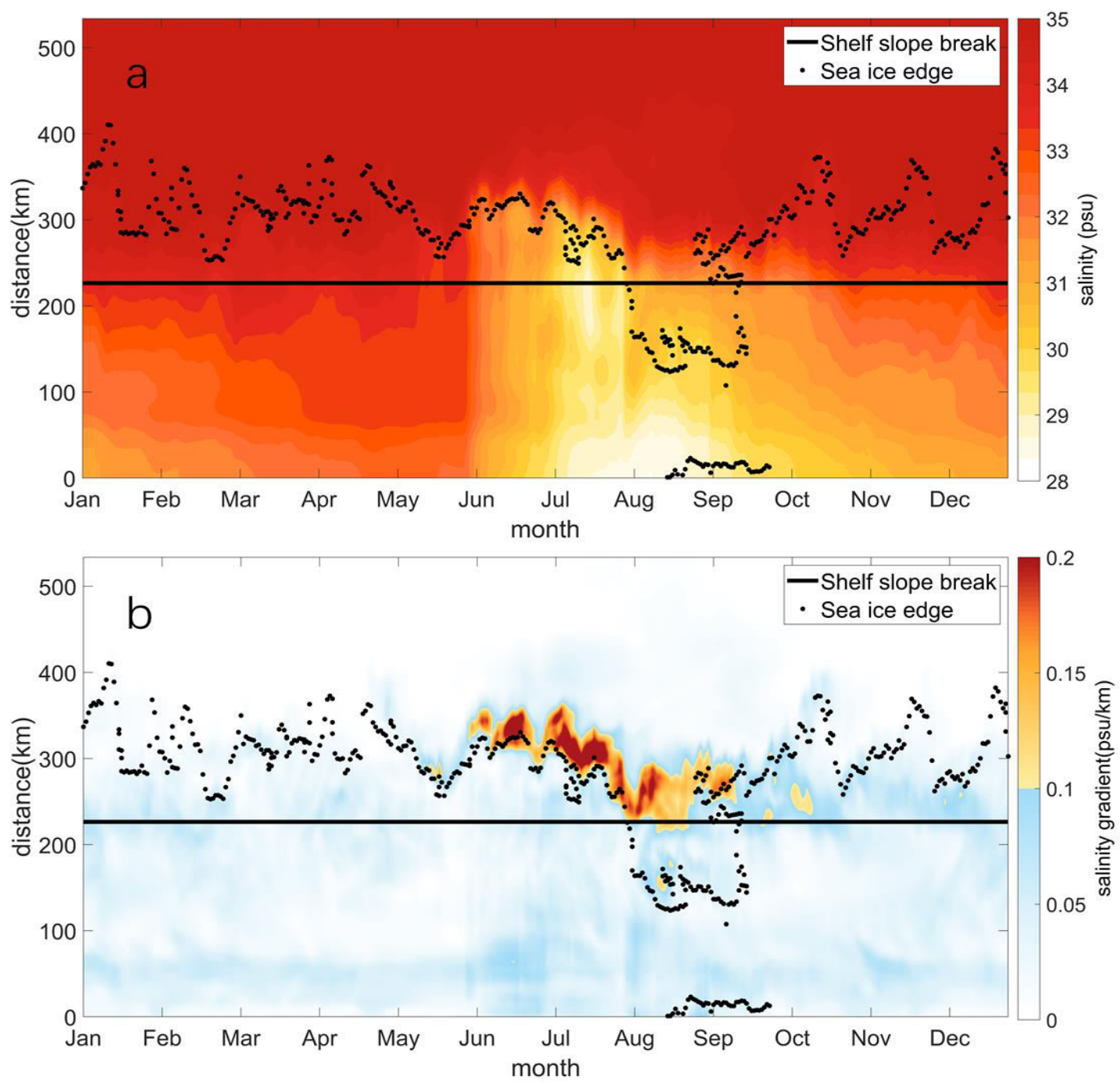

Figure 3. Daily variation of (a) salinity and (b) sea surface salinity horizontal gradient (background color) along the section (red line) indicated in Fig. 1. The black dots are the daily variation of the intersections between the marginal ice line and the section line. The abscissa is the time for 2007 and the ordinate is the offshore distance along the section line. The solid black line in (b) is the position of the shelf break along the section line.

With global warming, sea ice melting has accelerated in the Pan-Arctic 144 region ${ }^{21,22}$. The sea ice concentration with the minimum sea ice area in selected years 
is shown in Fig. 4a. The southern tip of the sea ice extent moves northward from $70^{\circ} \mathrm{N}$ to $75^{\circ} \mathrm{N}$ from 1995 to 2018 . The monthly average sea ice area in the Greenland Sea from June to September of 1993-2018 shows that the sea ice area has a decreasing trend.

Based on the observed (reanalysis) data, the JA average sea ice area in the Greenland Sea from 1993-2018 (Fig. 4b) has a decreasing trend of $5.83 \times 10^{3}(4.36 \times$ $10^{3}$ ) $\mathrm{km}^{2} /$ year. The variations are almost the same between these two data. The climatological (1993-2018) seasonal variation in the Greenland Sea (black line in Fig. 4c) shows that the sea ice area decreases rapidly in May, shrinks to the continental shelf in July (the continental shelf area is about $2.70 \times 10^{5} \mathrm{~km}^{2}$, marked with the solid red line in Fig. $4 \mathrm{c})$, and reaches its minimum $\left(7.58 \times 10^{4} \mathrm{~km}^{2}\right)$ in September.

To explore the sea ice melting-induced changes in the Greenland Sea salinity front, we use two indices, the front area and the averaged front intensity. The front area is defined as the area occupied by a high salinity gradient greater than a threshold. The averaged front intensity is defined as the average value of the high salinity gradient greater than a threshold. In the analysis, this threshold is set to $0.1 \mathrm{psu} / \mathrm{km}$.

In the climatological seasonal variation, the front area beyond the continental shelf increases rapidly in May, reaches its peak value of $7.80 \times 10^{4} \mathrm{~km}^{2}$ (solid blue line in Fig. 4c) and then decreases. The July-August surface front area is larger than in June and September (figure not shown). This is due to the rapid rate of sea ice melting in July and August, which results in a large influx of fresh water, thus inducing strong salinity gradients and increasing the frontal area.

In the Greenland Sea, the JA average front area beyond the continental shelf from 1993-2018 has a maximum of $1.03 \times 10^{5} \mathrm{~km}^{2}$ in 1996 and a minimum of $4.65 \times$ $10^{4} \mathrm{~km}^{2}$ in 1999 (solid blue line in Fig. 4d). The interannual variations of the upper front area with a strong gradient have a decreasing trend of $142 \mathrm{~km}^{2}$ /year (dotted line in Fig. 4d). The decreasing trends of the monthly average front area are obvious in July and August, and are relatively flat in June and September (not shown).

The seasonal intensity of the salinity front beyond the continental shelf (Fig. 4c) increases rapidly in May. It reaches its strongest $(0.22 \mathrm{psu} / \mathrm{km})$ in July and then 
decreases until April of next year. The lower intensity in September is due to the sea ice formation, which weakens the salinity gradient.

The interannual variation of the average intensity of the salinity fronts beyond the continental shelf in June and September increases year by year, and decreases in July and August (not shown). However, the amplitude of the front intensity has an overall decreasing trend of about $1.7 \times 10^{-3} \mathrm{psu} / \mathrm{km}$ (dotted orange line in Fig. 4d). The JA average intensity reaches a maximum (minimum) value of $0.24(0.18) \mathrm{psu} / \mathrm{km}$ in 1993 (2013).
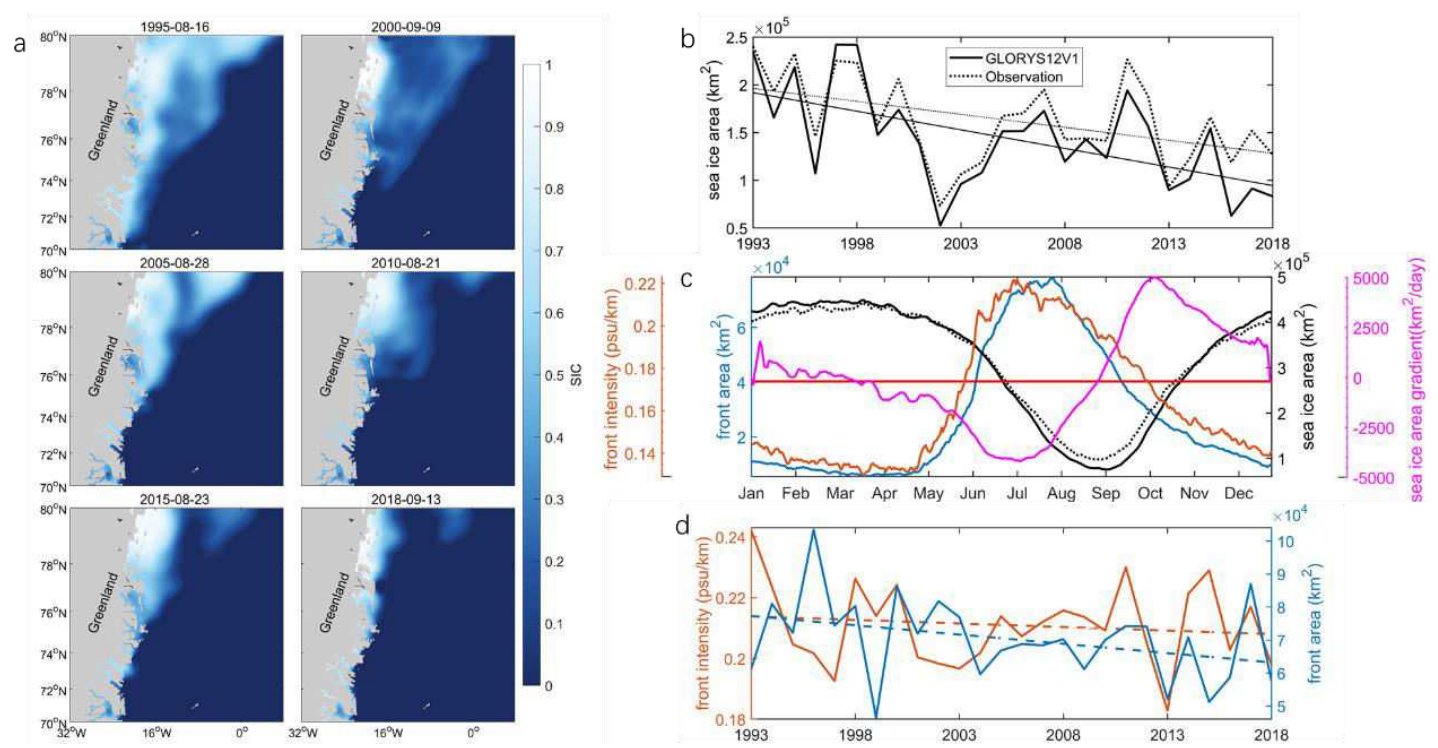

Figure 4. (a) Sea ice concentration with the minimum sea ice extent in 1995, 2000, 2005, 2010, 2015 and 2018. (b) Interannual variations of the July-August averaged sea ice extent. The solid (dotted) line is the satellite observation (GLORYS12v1) data. (c) The seasonal variations of the front area and intensity beyond the continental shelf, the sea ice extent and the variation gradient of the sea ice area. The red line represents the continental shelf area. (d) Interannual variations of the July- August averaged front area and intensity beyond the continental shelf.

\section{Conclusion and Discussion}

Based on the daily average reanalysis data from 1993 to 2018, the spatio-temporal variations of salinity front in the Greenland Sea are analyzed. The results show a significant spatial relationship between the main position of the sea salinity front and the position of the marginal ice edge before the sea ice shrink to the shelf break. In summer, the solar short-wave radiation increases, leading to a rise in air and seawater temperature. With the sea ice melting, the cold and fresh seawater meet with the warm 
and salty seawater in the open sea area and produce the salinity front. The front area with a strong salinity gradient is mainly distributed near the ice edge.

Affected by the formation and melting of the sea ice, the intensity and area of the salinity front show seasonal variations. The sea ice extent begins to decrease rapidly from May, while the average intensity and area of the salinity front begin to increase rapidly. When the sea ice extent shrinks to the continental shelf in July, the intensity of the salinity front reaches its strongest $(\sim 0.22 \mathrm{psu} / \mathrm{km})$. The sea ice continues to melt in the continental shelf. But due to the strong mixing effect of the seawater in the continental shelf area, the front is restricted to the continental shelf break. At this time, the maintaining mechanism of the strong salinity gradient steadily weakens in the shelf break, and the salinity front intensity begins to decrease. However, although the front intensity weakens due to the horizontal diffusion and mixing, the salinity front area is still expanded and reached its peak value $(\sim 7.80 \times$ $10^{4} \mathrm{~km}^{2}$ ) in August. After reaching the minimum value in early September, the sea ice extent increases rapidly until January of the next year, and then has a slight change from February to April. In the same period, the intensity and area of the salinity front beyond the continental shelf decrease from September to April of the next year.

In terms of interannual variation, the monthly average intensity of salinity front beyond the continental shelf increases in June and September and decreases in July and August. But overall, the amplitude of the front intensity has a decreasing trend of about $1.7 \times 10^{-3} \mathrm{psu} / \mathrm{km}$. The monthly average front area beyond the continental shelf also decreases year by year from June to September. It has a decreasing trend of about $142 \mathrm{~km}^{2} /$ year.

The sea ice extent from July to August dramatically decreases and has a decreasing trend of $5.83 \times 10^{3} \mathrm{~km}^{2} /$ year in the Greenland Sea. But the background surface salinity increases slightly. It may be the reason for the weakening of the salinity front gradient and the decreasing of the average intensity and area. The variation of the salinity front influences other oceanic processes, such as frontal eddies. Therefore, it is necessary to analyze the salinity budget and the variations in the oceanic processes related to the salinity front in the Greenland Sea. 


\section{Data and Method}

230 Satellite data. The sea ice concentration data from the Operational Sea Surface

231 Temperature and Ice Analysis (OSTIA) reprocessed product ${ }^{23}$ is used in this study. It 232 has a horizontal resolution of $1 / 20^{\circ}$ and the time range is from 1981 to 2020 . The 233 geostrophic current data is from the Archiving Validation and Interpretation of 234 Satellite Oceanographic (AVISO). It has a horizontal resolution of $1 / 4^{\circ}$ and spans 235 from 1993 to 2019. Both datasets are distributed by the Copernicus Marine Environment Monitoring Service (CMEMS; https://marine.copernicus.eu/).

Reanalysis data. The salinity data, a global ocean eddy resolution reanalysis product GLORYS12V1, also distributed by CMEMS, is used. It has a horizontal resolution of $1 / 12^{\circ}$ and 50 vertical layers. The time range of the data is from 1993 to 2018.

Methods. Some studies use the isobath of temperature, salinity or density to determine the existence of a front ${ }^{24,25,26}$. This method is suitable for the frontal analysis of profile data. In this paper, we use a front detection algorithm proposed by Belkin et al. (2009)26. The horizontal gradient field is calculated to determine the position and intensity of the salinity front.

First, we calculate the distance between every two grid points (equation (1)):

$$
d i s=2 \arcsin \sqrt{\sin ^{2} \frac{a}{2}+\cos (\operatorname{Lat} 1) \times \cos (\operatorname{Lat} 2) \times \sin ^{2} \frac{b}{2}} \times R
$$

where $a$ is the latitude difference Lat1-Lat2, $b$ is the longitude difference Lon 1 - Lon 2 and $R$ is the Earth radius $6378.137 \mathrm{~km}$. Then, we use the Sobel operator's convolution kernels $G X$ and $G Y\left(G X\right.$ rotated by $\left.90^{\circ}\right)$ to calculate the gradients $\left(G_{x}, G_{y}\right)$ in the $X$ and $Y$ directions, respectively. The calculation formula is as follows (equation (2)):

$$
G X=\left[\begin{array}{ccc}
+1 & +2 & +1 \\
0 & 0 & 0 \\
-1 & -2 & -1
\end{array}\right] \quad G Y=\left[\begin{array}{lll}
-1 & 0 & +1 \\
-2 & 0 & +2 \\
-1 & 0 & +1
\end{array}\right]
$$

$$
G_{x}=\frac{1}{4} * G X * A /\left(2 * d i s_{x}\right) \quad G_{y}=\frac{1}{4} G Y * A /\left(2 * d i s_{y}\right)
$$


where $d i s_{x}$ is the distance in $X$ direction between two grid points and dis $y$ is the distance in $Y$ direction. $A$ is the original salinity data. So, the gradient value $G$ is obtained by the square root of the gradient in the $X$ and $Y$ direction (equation (3)).

$$
G=\sqrt{G_{x}^{2}+G_{y}^{2}}
$$

The value $G$ is used to determine the position and intensity of the salinity front. The intensity of the front varies in different seas. In this paper, we choose $0.1 \mathrm{psu} / \mathrm{km}$ as the threshold value to define the salinity front in the Greenland Sea. In addition, we use two indices, the front area and the mean intensity, to describe the salinity front. The front area $S_{g}$ of the front is calculated as follows (equation (4)):

$$
\begin{gathered}
S_{i}=d i S_{x i} * d i s_{y i} \\
S_{g}=\sum_{i=1}^{n} G_{\text {mask }} \times S_{i}
\end{gathered}
$$

where $d i s_{x i}$ and $d i s_{y i}$ are the distances between two adjacent grid points in the horizontal and vertical directions, respectively. $S_{i}$ is the grid area. $G_{\text {mask }}$ is a matrix, in which the part corresponding to $G$ greater than $0.1 \mathrm{psu} / \mathrm{km}$ is set to 1 , and the rest is set to 0 . The average intensity of the front is defined as equation (5):

$$
\bar{G}=\frac{\sum_{i=1}^{n} G_{\text {mask }} \times G_{i} \times S_{i}}{\sum_{i=1}^{n} G_{\text {mask }} \times S_{i}}
$$

The above front area calculation method is affected by the resolution of the data grid, but the average intensity is not. In this paper, we use the average intensity and front area to analyze the variation of the salinity front in the Greenland Sea.

\section{References}

1. Amante, C. \& Eakins, B. W. ETOPO1 1 Arc-Minute Global Relief Model: Procedures, Data Sources and Analysis, NOAA Technical Memorandum NESDIS NGDC-24, National Geophysical Data Center, NOAA, doi:10.7289/V5C8276M (2009).

2. Kostianoy, A. G., and J. C. J. Nihoul (2009), Frontal zones in the Norwegian, Greenland, Barents and Bering seas, In Influence of Climate Change on the Changing Arctic and Sub-Arctic Conditions, edited by J. C. J. Nihoul and A. G. Kostianoy, 171-190, Dordrecht: Springer. 

front in autumn, Journal of Geophysical Research: Oceans, 90(C3), 4866-4882. 4. Manley, T., K. Hunkins, and R. Muench (1987), Current regimes across the East Greenland Polar Front at $78^{\circ} 40^{\prime}$ north latitude during summer 1984, Journal of Geophysical Research: Oceans, 92(C7), 6741-6753.

5. McPhee, M. G., G. A. Maykut, and J. H. Morison (1987), Dynamics and thermodynamics of the ice/upper ocean system in the marginal ice zone of the Greenland Sea, Journal of Geophysical Research: Oceans, 92(C7), 7017-7031.

6. Manucharyan, G. E., and A. F. Thompson (2017), Submesoscale sea ice-ocean interactions in marginal ice zones, Journal of Geophysical Research: Oceans, 122(12), 9455-9475.

7. Niebauer, H., and V. Alexander (1985), Oceanographic frontal structure and biological production at an ice edge, Continental Shelf Research, 4(4), 367-388.

8. Johannessen, J., O. Johannessen, E. Svendsen, R. Shuchman, T. Manley, W. Campbell, E. Josberger, S. Sandven, J. Gascard, and T. Olaussen (1987), Mesoscale eddies in the Fram Strait marginal ice zone during the 1983 and 1984 Marginal Ice Zone Experiments, Journal of Geophysical Research: Oceans, 92(C7), 6754-6772.

9. Mu, L., and J. Zhao (2013), Variability of the Greenland Sea ice edge, Advances in Earth Science, 28(6), 709-717.

10. Strong, C., and I. G. Rigor (2013), Arctic marginal ice zone trending wider in summer and narrower in winter, Geophysical Research Letters, 40(18), 4864-4868. 11. Brenner, S., L. Rainville, J. Thomson, C. Lee, and M.-L. Timmermans (2020), The evolution of a shallow front in the Arctic marginal ice zone, Elementa: Science of the Anthropocene, 8(1), 17.

12. Aagaard, K., and E. C. Carmack (1989), The role of sea ice and other fresh water in the Arctic circulation, Journal of Geophysical Research: Oceans, 94(C10), 14485-14498. 13. Deser, C., J. E. Walsh, and M. S. Timlin (2000), Arctic Sea ice variability in the context of recent atmospheric circulation trends, Journal of Climate, 13(3), 617-633. 14. Casas-Prat, M., and X. L. Wang (2020), Sea ice retreat contributes to projected increases in extreme Arctic Ocean surface waves, Geophysical Research Letters, 47(15), e2020GL088100.

15. Divine, D. V., and C. Dick (2006), Historical variability of sea ice edge position in the Nordic 
16. Markus, T., J. C. Stroeve, and J. Miller (2009), Recent changes in Arctic sea ice melt onset, freezeup, and melt season length, Journal of Geophysical Research: Oceans, 114(C12), doi:10.1029/2009JC005436.

17. Wadhams, P. (2005), BOOK REVIEW | Physical Oceanography of Frontal Zones in the Subarctic Seas, Oceanography, 18(2), 260-261. 18. Park, S., and P. C. Chu (2006), Thermal and haline fronts in the Yellow/East China Seas: surface and subsurface seasonality comparison, Journal of Oceanography, 62(5), 617-638.

19. Zhao, J., Y. Cao, and J. Shi (2006), Core region of Arctic Oscillation and the main atmospheric events impact on the Arctic, Geophysical research letters, 33(22), L22708.

20. He, Y., J. Zhao (2011), Distributions and seasonal variations of fronts in GIN seas, Advances in Earth Science, 26(10), 1079-1091.

21. Stroeve, J., and D. Notz (2018), Changing state of Arctic Sea ice across all seasons, Environmental Research Letters, 13(10), 103001.

22. Chatterjee, S., R. P. Raj, L. Bertino, S. H. Mernild, M. P. Subeesh, N. Murukesh, and M. Ravichandran (2021), Combined influence of oceanic and atmospheric circulations on Greenland Sea ice concentration, The Cryosphere, 15(3), 1307-1319.

23. Good, S., E. Fiedler, C. Mao, M. J. Martin, A. Maycock, R. Reid, J. Roberts-Jones, T. Searle, J. Waters, and J. J. R. S. While (2020), The current configuration of the OSTIA system for operational production of foundation sea surface temperature and ice concentration analyses, 12(4), 720.

24. Van Aken, H. M., D. Quadfasel, and A. Warpakowski (1991), The Arctic front in the Greenland Sea during February 1989: Hydrographic and biological observations, Journal of Geophysical Research: Oceans, 96(C3), 4739-4750.

25. Parsons, A. R., R. H. Bourke, R. D. Muench, C. S. Chiu, J. F. Lynch, J. H. Miller, A. J.

Plueddemann, and R. Pawlowicz (1996), The Barents Sea polar front in summer, Journal of Geophysical Research: Oceans, 101(C6), 14201-14221.

26. Belkin, I. M., and J. E. O'Reilly (2009), An algorithm for oceanic front detection in chlorophyll and SST satellite imagery, Journal of Marine Systems, 78(3), 319-326. 


\section{Acknowledgments}

Pawlowicz, R., 2018. "M_Map: A mapping package for MATLAB", version 1.4j, [Computer software], available online at www.eoas.ubc.ca/ rich/map.html.

This work is supported by the National Key Research and Development Program of China (2018YFA0605904) and by the Innovation Group Project of Southern Marine Science and Engineering Guangdong Laboratory (Zhuhai) (No. 311020004). Xiayan Lin is supported by the Natural Science Foundation of China project (41806030) and the Basic scientific research business expenses of Zhejiang Provincial Universities (2020J00007).

\section{Author Contributions}

J.W. and Y.L. initiated the idea, designed the study, analyzed the data and contributed to the writing of the manuscript. G.H., X.L. and G.Y. contributed to the revision of the manuscript.

Competing Interests: The authors declare that they have no competing interests. 